\title{
CHARACTERIZATION AND APPLICATION OF PETROLEUM SULFONATE SYNTHESIZED BY GAS-PHASE SO3 SULFONATION IN ROTATING PACKED BED
}

\author{
Xiaoke Ma ${ }^{1}$, Bin Liu ${ }^{1}$, Tianxiang $\mathrm{Ma}^{2}$, Hai-Kui Zou ${ }^{1}$, Guang-Wen Chu ${ }^{3}$, Baochang Sun ${ }^{4}$, \\ Liang-Liang Zhang ${ }^{3}$, Yong Luo ${ }^{1}$, and Jianfeng Chen ${ }^{1}$ \\ ${ }^{1}$ Beijing University of Chemical Technology \\ ${ }^{2}$ Affiliation not available \\ ${ }^{3}$ Beijing University of Chemical Technology College of Chemical Engineering \\ ${ }^{4}$ Beijing Univ Chem Technol
}

May 6, 2020

\begin{abstract}
In this study, PS was synthesized by gaseous SO3 sulfonation of distillate oil in a rotating packed bed. The chemical compositions of the prepared PS and its raw material (distillate oil) were obtained by the combined analysis of the double-bond equivalent and carbon number at the molecular level. In addition, the EOR performance of PS has been studied by measuring surface tension, interfacial tension (IFT), wettability alteration and core-flooding experiments. An ultra-low IFT value $1.327 \times 10-3$ $\mathrm{mN} / \mathrm{m}$ between the crude oil and prepared PS solution was obtained at the critical micelle concentration (CMC) of PS solution. Core flooding experiments showed that additional oil recoveries of $28.10 \%$ and $30.77 \%$ were obtained at PS concentrations of $0.3 \%$ and $0.6 \%$ respectively after conventional water flooding, indicating the prepared PS has good performance on EOR.
\end{abstract}

\section{Hosted file}

manuscript-characterization and application of petroleum sulfonate.docx available at https://authorea.com/users/319022/articles/448822-characterization-and-application-ofpetroleum-sulfonate-synthesized-by-gas-phase-so3-sulfonation-in-rotating-packed-bed 